\title{
A Participatory Modeling Process to Capture Indigenous Ways of Adaptability to Uncertainty: Outputs From an Experiment in West African Drylands
}

\author{
$\underline{\text { Patrick d'Aquino }}^{l}$ and $\underline{\text { Alassane Bah }}^{2}$
}

\begin{abstract}
Over the centuries, local communities have shaped atypical rules to deal with the uncertainty of their environment. They have developed complex prototypes for flexible overlapping institutions and arrangements to adapt their rules and uses to their uncertain environment. Today, this indigenous way of flexibly institutionalizing access rules could provide blueprints for dealing with uncertainty issues resulting from global change as well as designing practical guidelines for implementing resilient management. However, transforming indigenous skills for developing institutional flexibility into operational management rules that are appropriate in the current environmental and socioeconomic context is a huge challenge. However, communities could easily succeed in this reframing because the structuring principles of institutional flexibility are embedded in their mind frame. In this perspective, a participatory modeling process was applied in Senegal to explore, first, how to design a methodological platform to enable local people to shape different forms of environmental management and policies they consider appropriate in the new context of environmental uncertainty by drawing on their own attitudes to environmental management. Second, to increase the value of such "self-designed" outputs in improving knowledge about, and improving, the practical management of uncertainty, especially in drylands.
\end{abstract}

Key Words: environment; indigenous knowledge; management; modeling; participation; Sahel; Senegal; uncertainty;

\section{INTRODUCTION: "SURFING ON UNCERTAINTY," AN INDIGENOUS WAY OF THINKING THAT COULD BE USEFUL FOR THE RESILIENCE FRAMEWORK}

Embedded in deeply uncertain contexts, indigenous communities progressively developed particular ways of thinking about how to organize access to nature in a way that "surfs on uncertainty" rather than contending with it (Berkes and Folkes 1998). Sahelian societies are a prime example of such surfing because for centuries they have had to craft rules and practices to cope with deep uncertainty and environmental scarcity (Ellis and Swift 1988, Westoby et al. 1989, Behnke et al. 1993, Scoones 1995, Mehta et al. 1999, Fraser et al. 2006, Nylong et al. 2007, Moritz et al. 2009). Drylands farmers may use different practices in the same field, for example, spreading manure on only one part and hoeing another, i.e., increasing their range of practices to have included the practice that is best adapted to the uncertain climate that year. In the same way, in response to the spatial uncertainty of rainfall and to avoid uncontrolled access, herders shaped collective rules for open access to land based on subtle social agreements that may vary from family to family and from village to village. These rules enabled many different uses for each piece of land (Basset and Crummey 1993) because they allocated specific rights of access for each possible use of each natural resource, such as cultivating annual crops, planting an orchard, creating a pasture, hunting, gathering wild fruits, collecting firewood or fodder, or harvesting wood for crafts. In addition, rights of access may change with the season and with the duration and the economic value of the activity, an annual or perennial crop, fruit trees, or gum trees, among others. Rather than being interpreted as land ownership, these complex access rights should be seen as a bundle of rights that control the appropriation, exploitation, and use of natural resources in a given space. On the whole, traditional practices and livelihood strategies are based on diversity, whether of seeds, livestock breeds, technical practices, or land uses, and on the resulting flexibility with the aim of improving their adaptability (Juul 2005, Mortimore 2005, Scoones 2009).

Furthermore, the institutional arrangements and regimes are tailored to enable this flexibility (Mehta et al. 1999, Fairhead and Leach 2005, Ostrom 2005). Collective rules for the management of access to resources have been crafted to support and even increase flexibility and reactivity. As a result, in many cases, the natural resources of drylands are managed through a mix of institutions and arrangements derived from flexible negotiations about access rights (Mehta et al. 1999) with some landscape patches managed exclusively, and others managed intermittently as exclusive resources and at other times more loosely; in other words, a whole society's adaptation to nonequilibrium ecological dynamics (Westoby et al. 1989, Behnke et al. 1993, Scoones 1995, Dougill et al. 1999, Thébaut and Batterbury 2001, Moritz et al. 2009). Conversely, formalized, nested, regulatory structures appear to be too inflexible and cumbersome to respond to the need for flexibility. Privatization or closure of such pastures have been shown to be inefficient in an environment in which the location of resources shifts to such an extent that carrying 
capacities cannot be static (Perkins and Thomas 1993, Dougill et al. 1999, Fraser et al. 2006, Hesse and Thébaud 2006).

Admittedly, demographics and the climate have changed, and some Sahelian rules and practices are less appropriate today. However, at a time when the world is looking for principles to increase the adaptability of society (Gunderson 1999, Hagmann et al. 2002), this type of indigenous background to institutional adaptability could help envisage novel principles and mechanisms to increase the adaptability of society's interactions with nature.

Drawing on such indigenous frameworks to design modern forms of regulations is a huge challenge. These frameworks cannot be grasped by simply recording present or past rules, which are merely contextual applications and may not be suitable for other contexts. Indeed, with our western way of thinking, we may not succeed in fusing such a fuzzy institutional perspective and overlapping structure. However, drylands societies have succeeded in doing so. It is a part of their mind frame and of their own perception of collective organization. So letting them design rules based on their complex and 'fuzzy' institutional context is an interesting avenue of exploration.

Our method explores a twofold hypothesis: first, the ability of a specific participatory modeling process to enable endogenous ways of thinking about environmental management to be elicited and self-expressed in a form that is compatible with modern policies and management measures. Second, the ability of drylands societies to shape useful policy frameworks on their own based on their indigenous principles of institutional adaptability. To this end, we used a participatory modeling process focused on letting participants design their own model of local management options, and we presented it in a way that encouraged the participants to think about their background principles rather than only about their local management issues. This was achieved by first getting them to focus on their own perception of the overall policy challenges, then by providing a multiscale spatial representation they could use to express their opinions about and deal with these policy challenges, and last, through the multilevel implementation of this process, by bringing together groups of stakeholders from different locations and social levels in the modeling process.

\section{METHOD: THE "SELF LAND POLICY" MODELING PROCESS: A SPECIALLY DESIGNED METHOD TO LET INDIGENOUS THINKING FRAMEWORKS EMERGE}

The specific participatory modeling process we used in the experiment was designed and implemented in the late 1990s in Senegal with the aim of improving participatory supports for local environmental management. Existing participatory approaches can be improved from both epistemological and methodological points of view. First, they were shown to be overly influenced by the facilitators', scholars' or modelers' points of view to really represent a local voice (Gardner and Lewis 1996, Agrawal and Gibson 1999, Selamna 1999, Stringer et al. 2006, d'Aquino 2007, Medema et al. 2008). Second, the participatory tools available at the time were not efficient enough: many of the real incentives behind local behaviors are not openly expressed at collective meetings, and it is difficult to get stakeholders to think about the future consequences of the current dynamics, which are not yet apparent (d'Aquino et al. 2002). The self-design approach developed in the late 1990s has been shown to overcome methodological hurdles by using role-playing games to enable stakeholders both to express themselves in a much freer social arena than a simple collective meeting, and to more cleverly consider the future effect of current situations. The self-design approach has also been shown to enable progress in overcoming epistemological problems by letting stakeholders design their own model of an issue with much less influence from scholars (d'Aquino et al. 2003). Our approach is close to the ground theory (Martin and Gynnild 2011), but the emphasis is not on using grounded data for our own conceptualizing process but for the stakeholders' process, in other words, a grounded conceptualization.

Indeed, the self-design process ensures the respect of diverse points of view about an issue by enabling each participant not only to make sure his/her point of view is included in the collective appraisal, but also to better understand the other participants' points of view. The method preserves this diversity in three ways: (1) by making sure the variety of users' logic is reflected in the players' roles, (2) by retaining all the different opinions about what is a good and bad goal for a policy, in other words different assessment indicators, and (3) by ensuring the range of different points of view about the environment remains intact. This is the main difference between our approach and many other participatory approaches: our aim is not to reach a consensus on the issue and its solution, but a shared acknowledgement of the variety of points of view about the issue and possible solutions. Based on this shared acknowledgement of a wide range of options, the aim of the approach is to launch an autonomous exploration of potential solution scenarios (d'Aquino et al. 2002). The outcome of these experiments in the early 2000s informed an innovative participatory modeling approach called companion modeling that focused on environmental management by dissimilar stakeholders (Barreteau et al. 2003a, Bousquet et al. 2003, Étienne 2011).

The method thus first aims to help people to think about the general principles behind their own adaptability rather than focus on their local personal issues concerning natural resources management. Second, it aims to have them try and transform the adaptability principles of their society into a concrete policy framework that can be implemented at the state level. 


\section{An incremental inclusionary strategy}

The process has the huge ambition of mobilizing the abilities of an entire targeted society. In an operational perspective, the challenge is to involve stakeholders at different locations and at different levels of society within reasonable means. Therefore the strategy lies on the incremental involvement of the different stakeholder groups by progressively adding new groups to previous groups in a two-year process. The first challenge of the method is to maintain a balance between the different stakeholders' views because they are being progressively integrated in an ongoing process. To achieve this goal, the participatory arena in fact comprises several separate workshops held with different stakeholder groups, but interlinked by the same model design. The second methodological challenge is to enable efficient links to be created between the different groups.

This incremental inclusionary strategy has a second key objective: launching the process with people who are truly motivated to draw on their own abilities to develop proposals for a new policy framework. Respecting this incremental framework, we first present our approach to the stakeholders in a proposal meeting, and then let them inform us if and when they are interested in becoming involved. Moreover, as no financial compensation is provided for their participation in the workshops, the interest they show at this point is the first sign of commitment. This proposal meeting, which can easily be held during the same period with many different stakeholder groups including different villages, district councils, or user groups, is the first step in the process.

\section{First requirement, a high level of explicitness concerning the method and its scope}

Because the stakeholders' stated commitment is needed before the process is launched, our proposal has to be explained very clearly and in considerable detail at the first meeting. The first point concerns its scope: we explain clearly that we propose to help them to draw on their own empirical and cultural knowledge to design a number of policy options because we think this could culminate in interesting innovative policies. We emphasize that the expected outputs will not focus on their local issues and, consequently, will have no guaranteed local impact, but will rather focus on an overall policy framework whose outputs we will then use together to try to influence their decision makers.

We will be using the self-design method, which is explained in practical terms, because the same high level of explicitness is required. First of all, we explain the scope of the self-design process applied to policy design, which enables each local stakeholder to better embed his/her point of view in the policy framework and also to better understand the policy makers' points of view. Next, the different steps of the process are explained in detail, but most importantly, a prototype of a companion modeling role-playing game is presented. Discovering the game and its philosophy is the best way to understand the scope of the method.
After the proposal meeting, people are asked to contact the team if they would like to be involved. In 2008, this kind of meeting was held with several user groups, villages, and district councils in different parts of Senegal, which were selected because they represented the wide range of land use issues, i.e., the Senegal River basin, the Ferlo sylvopastoral area, and the southern groundnut area, as well as the diversity of society's experience, i.e., from very local users to national leaders. A proposal meeting concerning land tenure reform was also held with an interministerial group and included some representatives of civil society.

\section{A process with three participatory stages}

Once a stakeholder group has asked to be involved, the following process is implemented (d'Aquino and Bah 2013a). During the self-eliciting stage, the participants themselves decide on the scope of the future simulation model. They identify the policy challenges from their own points of view and values, in such a way that all the different points of view are reflected (Fig. 1), and identify the key constraints implied by the policy challenges as well as their livelihood needs. Indeed, defining what is at stake depends on deeply rooted values and perceptions. The main thrust of this step is to preserve and respect the variety of points of view.

\section{Self-designing stage}

Next, the objective of the self-designing stage is to let participants build a role-playing game to represent their view of their context of environmental uncertainty. In our companion modeling approach, role-playing games enable people to design a conceptual model of their issue (Bousquet et al. 2002, Barreteau et al. 2003b). A basic role-playing game is presented to the participants. The structure of the roleplaying game must not represent the modeler's perception of the issue. The goal is not to have participants progress toward the modeler's knowledge system, but to let them design their own conceptual model based on their own worldview.

This is why the structure of the game, which is based on the outputs of the first self-modeling experiments at the local level (d'Aquino et al. 2003), is kept very simple (d'Aquino and Bah $2013 b)$. The first component is the setting, which is represented by a spatial grid (Fig. 2) comprising the environmental units identified by participants in our original experiments. The second component is the different types of users of the environment, i.e., the role-players in the game. The social roles, for example, local representatives of village chiefs, are not defined as role-players before the game begins. They are described as the additional status of a user: in the game, participants will play their social role in addition to their user role whenever they feel the need to do so, and in the way they decide collectively at this time. The social organization and negotiations are not predetermined by the game but are left to the participants to define. 
Fig. 1. Some of the policy challenges that emerged from the self-eliciting workshops.

\begin{tabular}{|c|}
\hline Increasing production \\
\hline Increasing productivity \\
\hline Securing development and investment \\
\hline Providing bank guarantees to farmers \\
\hline Preserving a sufficient landholding for family farms \\
\hline Conserving natural resources \\
\hline Improving adaptive capacities \\
\hline Regulating competition for land with high potential (wetlands, peri-urban) \\
\hline Soft rules allowing multi-purpose uses of the same land \\
\hline Allowing transhumance and increasing herd productivity \\
\hline Facilitating complementarity of crops and livestock raising \\
\hline Responding to population growth \\
\hline Preserving community identity and cultural values \\
\hline Harmonizing common and official systems \\
\hline Preserving social peace and cohesion \\
\hline Being aware that each user needs to exchange with others \\
\hline Improving negotiation \\
\hline Keeping local responsibility for environmental protection \\
\hline Strengthening borrower's land use rights as investment incentives \\
\hline Strengthening lender's land rights as borrowing incentives \\
\hline Strengthening deprived groups' land rights for poverty reduction \\
\hline Ensuring people's free access to land, water, and other vital resources \\
\hline Preserving particular uses (e.g. pastoralism) \\
\hline Harmonizing texts and land practices \\
\hline Improving knowledge and respect for collective action (local or official) \\
\hline Clarifying land boundaries to reduce conflicts \\
\hline
\end{tabular}

Fig. 2. The board used for the role-playing game.

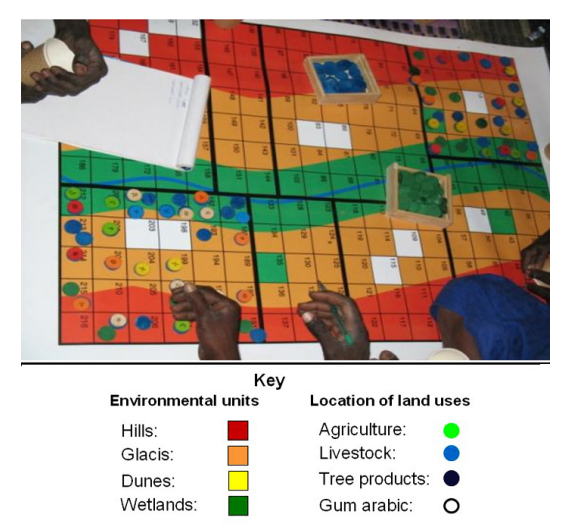

At this very early stage, the range of user roles is quite basic, i.e., large scale farmers and smallholders, because the aim is to let stakeholders build their own typology. The third components, pawns that represent the players, are colored according to the activity the player chooses. The fourth component is tokens that enable qualitative assessment of the level of self-sufficiency in livelihood needs that each player reached during the game. Finally, a number of rudimentary qualitative indicators of sustainability, which were selected among the policy challenges the participants identified during the first eliciting stage, are included (Fig. 3).

Next, the participants are asked to locate the activities they wish to pursue in successive seasons on the game board map. A very simple rule defines the success of all activities: the combination of the amount of rainfall in the year concerned, which is randomly chosen by throwing a dice, and the environmental unit (see Fig. 2) assigned to the parcel. When rainfall is low, only one third of the activity pawns the player invests in a parcel are transformed into production units, represented by tokens, whereas two thirds of the tokens are transformed when rainfall is moderate, and three thirds when rainfall is high. This rule is introduced so that the participants realize a rule is needed for this purpose. The last rule is that certain activities require the entire parcel, meaning that other activities cannot be carried out in the same parcel at the same time. With respect to this, we do not lay down access rules but only highlight the practical implications of competition for a particular space: the players themselves will subsequently decide on the rules of access. Thus the game is structured by only three simple elements: a board with simple environmental parcels, local users as players, and some very simple rules for resources exploitation. Then the players define the more complex rules, e.g., access rules, ecological dynamics, etc. Participants can chose the activities they wish to pursue, position the pawns representing these activities on the board, and then move them around from one board map to another. So what is presented to the stakeholders is not a complete game, but the basic elements with which they can create a game while playing first with these elements.

As soon as the participants understand the game settings well enough, i.e., by actually playing the game, they are asked to thoroughly check and correct the structural elements, if need be, by enriching the spatial legend, extending the list of potential uses, changing the colors, and so on. They are also asked to define the rule for the impact of high, moderate, and low rainfalls on productivity in a qualitative way. They then correct the initial map to accurately represent their own regional environmental context. This request is deliberately left vague, particularly the scale, because the goal is to let the participants express their perceptions as freely as possible without referring to a frame built from another perspective, ours. However, participants are informed about the level of detail they need to depict, i.e., sufficient detail to include the 
Fig. 3. Participatory framework for coassessment of the scenario indicators designed.

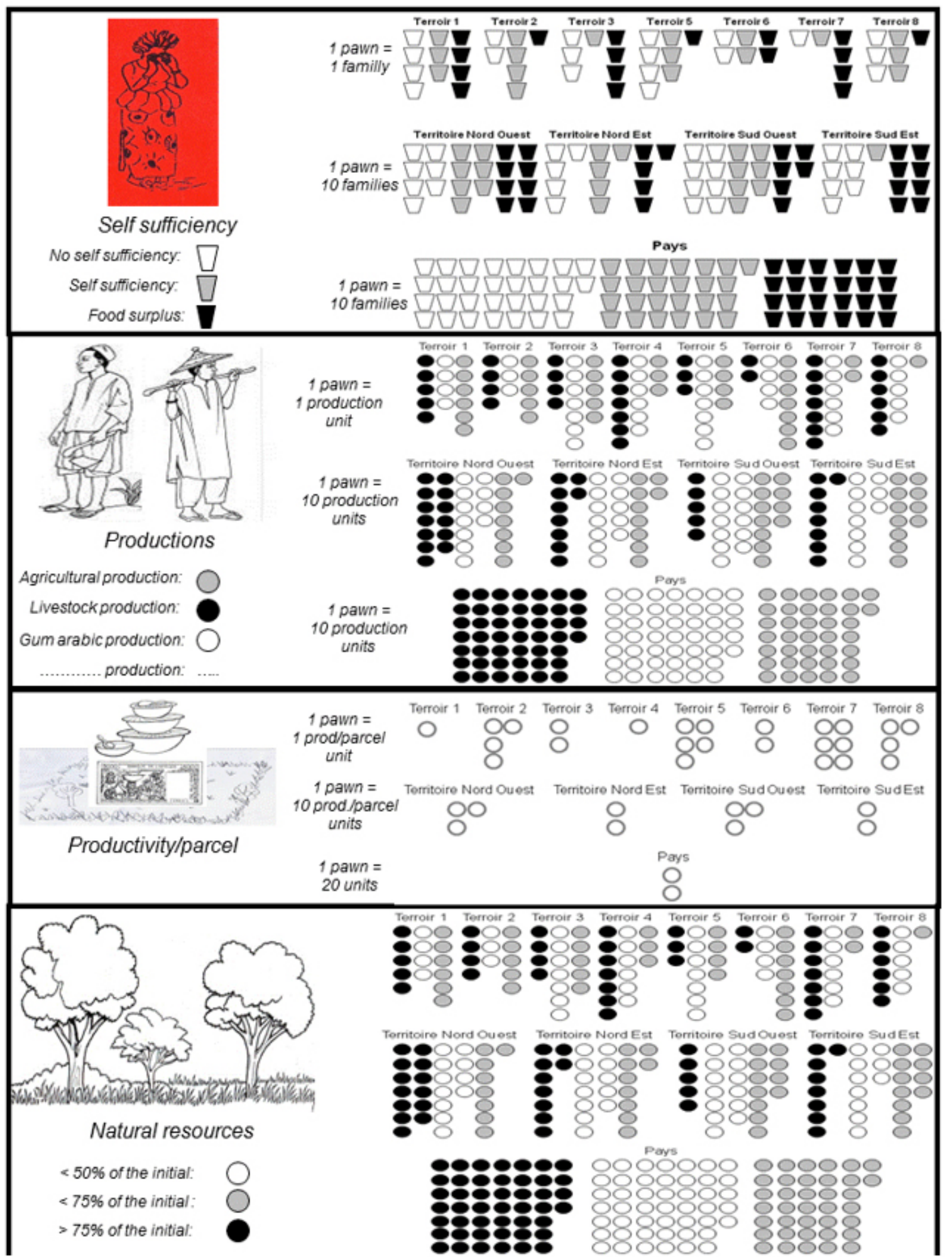


local features they consider to be crucial, but sufficiently summary to enable analysis at a national scale, in other words, so policy makers will be able to understand the game from their own point of view. The aim is to obtain a new map for the board game that represents the summary geographical structure of their environmental context and that highlights the points they consider to be important. Last, participants are helped to check to what extent the different policy challenges they identified previously (see Figs. 1, 3) can be assessed by playing the game, for example, the livelihood of each type of stakeholder they think should be taken into account, the constraints they consider important to deal with for sustainability, and so on. Then, with the facilitator, they think about how to modify the game settings to include the missing elements.

During this process, the structural components of a metaconceptual model are built progressively and can be used to prepare a more operational role-playing game, as well as a computerized version using an agent-based model (ABM). Both the board game and the computerized version are left sufficiently open to be enriched and contextualized in a continuous and iterative companion process, as the participants' knowledge system itself progresses (Étienne 2011). For instance, participants may progressively include new items like risk events, i.e., climate, bush fires, prices of goods, etc.; new forms of land use, i.e., intensive farming, hunting, tourism, etc.; social behaviors, i.e., users' or managers' strategies, forms of negotiation for access to land, etc.; or collective rules and organization, i.e., decentralization, common pool resources, etc.

\section{Self-modeling stage}

At this point, the self-modeling stage, the stakeholders are able to use the game, even the computerized version, to design and test environmental management options (d'Aquino et al. 2003): land tenure systems, rules of access to the different natural resources, forms of decentralization, etc. At the end of each game round, participants judge the management scenario they have just played, or tested on the computer, thanks to the evaluation indicators they themselves designed previously (see Fig. 3). They then create a new scenario of rules they think will be more efficient and test it. This is what we call a self learning-by-doing iterative process.

In practical terms, while playing the game, the participants play the role of local users who consume natural resources and also define the rules of access that apply to the players-users. In the computerized version, computerized agents act as users with the same incentives as the role-players in the board game, but the participants no longer actually play, they only define the collective rules that apply to the agents. The two forms of the same conceptual model are complementary. Board game sessions are used to help stakeholders tailor their own representation of the Sahelian environment and its management challenges, whereas the computerized participatory sessions are used to test more detailed and operational scenarios. Although the social complexity is clearly more efficiently apprehended by playing the game because players can improvise new behaviors and practices, biophysical and long-term dynamics are more efficiently apprehended using the computer. The computerized version is perhaps less user-friendly than the game but enables more complex environmental dynamics to be tested. The participants can consequently use the computerized model for in-depth exploration: they build their own scenarios for access rules, then simulate their application, and monitor their effects using the same evaluation framework as in the board game. In other words, the role-playing game supports the self-design of their conceptual model of environmental uncertainty, and the computerized version supports a more accurate simulated use of this conceptual model. As a result, the self-modeling process includes three specific participatory stages, in which the facilitator and modeler have a very limited but precise influence (Fig. 4).

Fig. 4. The specific participatory position in the self-design process.

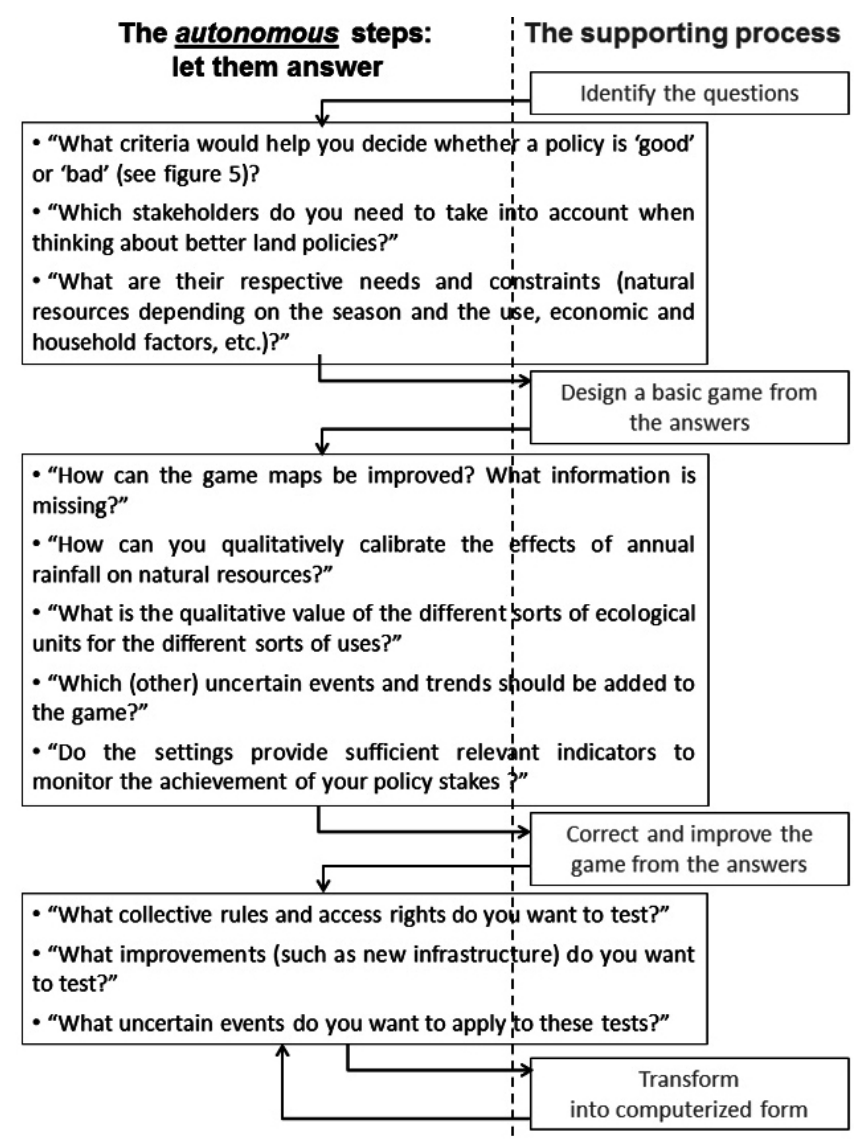




\section{A multiscale focus}

The multiscale focus of the modeling supports is another methodological strategy that helps participants to elicit their background worldview about how to manage uncertainty. First, to mobilize the scattered and intuitive skills of drylands society about institutional adaptability, the self-design process is implemented in parallel and through incremental involvement of different groups at different scales and social levels, e.g., families, villages, community representatives, or national leaders, and from the different agro-ecological regions of Senegal and beyond, i.e., (Mali, Burkina Faso. This means that the self-design process is used at different times with different groups because new groups are progressively incorporated. This is possible because the modeling structure allows the continuous addition of new user roles, as well as new, and even dissimilar, impact indicators for policy objectives. In addition, a multiscale representation of the Sahelian environment is supplied with the game. We observed that during the self-design process, the participants designed their own board map by looking at a national picture of their local environmental conditions. However, the game board does not present only one but several regional maps describing other regional drylands (Fig. 5). This is a recently added feature to enable incremental multilevel modeling between different groups of stakeholders and using the different skills of a society, a progressively widening design process to enable some societal background principles of adaptability to be shaped.

Moreover, we believe this multiscale representation encourages participants to think about management rules that are not only appropriate for their own very local setting, but also for other places and at other scales. The multiscale representation also enables participants to handle both the logic of uses, i.e., mobility, and the environmental management options at several scales. However, this is not a true multiscale representation because the embedded scales of the game board maps are vague and virtual reflecting our efforts to achieve an open-scale way of thinking about environmental policy options.

As a result of the multiscale representation, every new group works on the same model but can add new points of view, that is, new maps, or user's logic, policy challenges, and their own indicators, etc., if the need arises. Consequently, the exchanges between groups are iterative and incremental: each new group retrieves the latest version that has incorporated inputs from previous groups. We can consider this process to be an anthropological investigation because it is not structured by prior sampling, but according to the incremental logic of snowmarble sampling in sociological surveys. When no new information is gained by new interviews, in our case a new group, the process is considered to be complete. Consequently, sharing between groups is not completely equitable because the first groups do not know what proposals will be put forward by later groups. The challenge of the process, at least at this stage, is to try to efficiently gather the scattered knowledge and skills of the society rather than create a true democratic procedure. And accessing skills scattered throughout Senegal and beyond requires ranging as widely as possible rather than trying to initiate a deep exchange between specific groups.

Fig. 5. The multiscale structure of the model. The playersusers can move around on a map, move from one map to another, and from one season to another depending on their needs. Because participants can change maps depending on their context and scale, this multiscale representation enables different scales to be modeled depending on the range of scales chosen by the participants: the spatial unit selected can be a farm parcel, all the land belonging to one farmer, or even a local landscape. At the 2nd level, the spatial unit can be all the land belonging to a farmer, a communityÂ's territory, or even a region. At the 3rd level, the spatial unit can be a region, a whole country, or even an international region.

Example of a simulation board with 4 « maps »

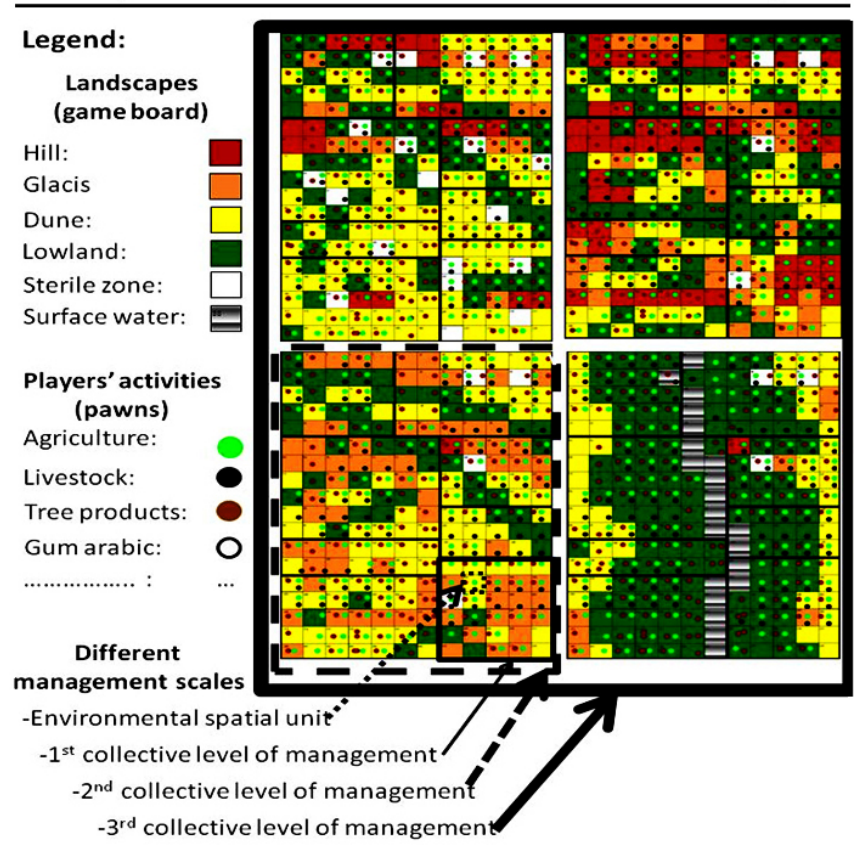

The multiscale focus we chose thus has two aims. One is to express the whole Sahelian multiscale logic, or even openscale logic, and the other is to ensure stakeholders are able to deal with the higher than local scope of a policy decision.

In Senegal, five self-design modeling processes were implemented in collaboration with villages between 2008 and 2010: two with district councils, one with an informal pastoralist network, one with an interministerial committee 
about a land tenure reform, and one with a village. Depending on the context, this three-stage self-design process can be accomplished in one, two, or three separate workshops. The method is more efficient with around 20 people, but has been organized in a way that enables some results to be achieved with more than 50 people, using several maps (Fig. 6). All these groups used and enriched the same modeling supports, i.e., the game and the computerized version. In fact, after several self-design processes, the structural elements of the supports, like the typology of environmental units and the livelihood needs of each stakeholder, no longer changed, resembling the snowball phenomenon observed in sociological surveys. Ongoing improvements of the supports are limited to adding new maps, i.e., regional landscapes, and enriching the complexity of the policy scenarios.

Fig. 6. A game session with different board maps, allowing many participants to be involved.

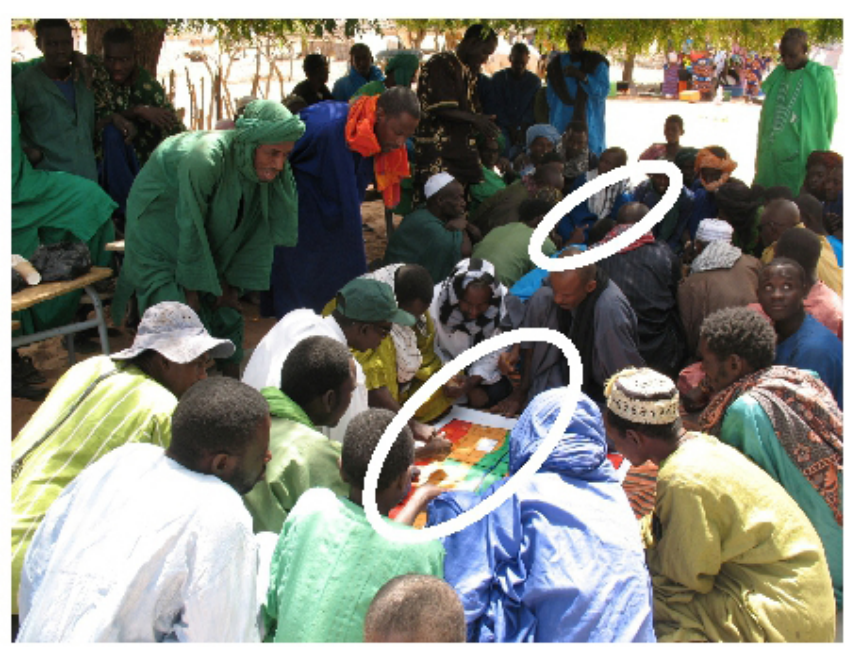

FIRST RESULTS: AN APPROPRIATE METHOD FOR SELF-ELICITING A LOCAL SOCIETY'S POINT OF VIEW

\section{Stakeholders' ownership of the method}

Our original hypothesis that these stakeholders are able to master the process to the point of expressing background opinions and behaviors was confirmed. First, dealing with a medium-term policy instead of with their urgent local needs was sufficient to motivate the majority of groups we contacted in our first proposal meeting. The participants were motivated both by better understanding policy makers' points of view and by having their own points of view acknowledged by decision makers. Accordingly, all the participants financed their involvement in the workshops. Many even insisted on introducing the same procedures in communities in other parts of the country with which they have land use agreements. Some stakeholder groups, including villages, district councils, or user federations, who had heard about the approach from the participants, also asked to be involved. We consider this endogenous dynamics to be the first successful step toward the internal policy momentum that is our long-term goal. As a result of this dissemination by word of mouth, our team has not been able to implement the design process with all the stakeholder groups who have asked us so far.

Second, the stakeholders demonstrated that they were able to correct the initial game settings in a meaningful way, for example, to change the ratio of the different environmental units in the game map to better fit their geographical context. In some cases, they even wanted to change the geographical structure, for example, to distribute lowlands not within the linear structure of a river basin, but by scattering them throughout the landscape. This means they not only grasped the mapping support despite its schematic representation, but also the idea of incorporating only the structural and other key elements required for management of the uncertainty depicted in the maps.

Third, they were very interested in correcting the rule concerning the relationships between the amount of rainfall per year and production. They carefully debated how to define this qualitative ratio.

Fourth, they used the rule-free feature of the game to conduct users' negotiations for access to resources entirely on their own. They even introduced some common masked behaviors into the game by themselves. For example, in a workshop in Mali, a local elected official played the role of a corrupt official to bring this problem into the open with the aim of improving the efficiency of a land policy.

More broadly, participants revealed their incentives and demonstrated their abilities to incorporate an eclectic list of relevant policy challenges (Fig. 1) to ensure everyone's point of view was included. Both local stakeholders and policy makers, quite surprisingly on the part of the latter, showed great interest in incorporating the other stakeholders' indicators. Indeed, they were interested in designing innovative policies by mixing local and policy frameworks. Last but not least, their use of self-modeling led to some unusual principles of uncertainty management.

\section{The emergence of specific uncertainty features from the self-design process}

The first fundamental element that participants introduced in the game settings was a qualitative calibration of the relationships between the amount of rainfall in one year and production. They were asked to qualify the difference in productivity between years with high, moderate, and low rainfall. Because the computerized version of the game enables variations in the different qualitative calibrations of the game, 
the effects of selecting the stakeholders' ratio can be simulated. However, while running the model, the only way to reveal the difference in productivity between high, moderate, and low rainfall years, defined by the stakeholders, was not to simply reduce the direct impact of rainfall on the production of resources, but also to increase the scarcity of resources (Fig. 7). Moreover, figure 7 shows that the conditions described by the stakeholders resulted in a simulation support in which a slight difference in resources availability caused a considerable difference in productivity. Thus, behind its apparent qualitative simplicity, the model simulation support provides an interesting representation of Sahelian uncertainty conditions based on a fine balance between the scarcity of resources and rainfall. Because of the way the stakeholders calibrated this fragility, the most advantageous use can vary even in the case of limited environmental variability (Fig. 8).

Fig. 7. Impact of variation in rainfall on different types of production in the computerized version of the game, according to the scarcity of natural resources. The graph shows the results of a series of computer simulations in which natural resources in the landscape vary (see $\mathrm{x}$ axis: rate of available resources). The y axis shows the rate of production depending on the yearly rainfall: a higher curve means a greater effect of rainier years on productivity. Consequently, the peak of the greatest impact of rainier years is in the middle of the graph when resources are least scarce, i.e., following better environmental conditions when a rainy year is less useful, and before resources become so scarce that even rainy year cannot have really beneficial impact. Actually, the qualitative model calibrated by local stakeholders in the game sessions matches the period when the impact of rainfall on productivity is highest, and the rainiest years provide the greatest benefit: participants instinctively shape a model that summarizes the specific conditions of land uses in the Sahel, and thus produce a user-friendly model that can be used to help design policies to fit these particular conditions.

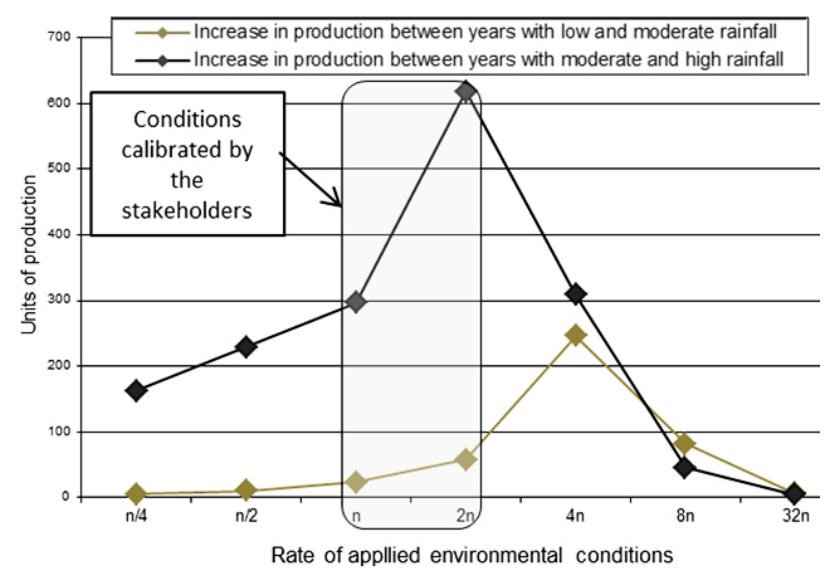

Fig. 8. Productivity of the three major uses according to the level of resource scarcity, including the impact of rainfall. The $\mathrm{x}$ and $\mathrm{y}$ axes are the same as in the previous graph, i.e., $x$ axis: the varying parameters of natural resources in the computer model; $y$ axis: users $\hat{A}$ ' production according to the availability of resources. The box highlights the same area as in the previous graph: the qualitative conditions of available resources designed by stakeholders during the selfdesigned game. Although the previous graph focuses on the greater impact of climate in the stakeholders $\hat{A}$ ' model, this graph highlights another feature that also only comes to light in the environmental conditions designed by the stakeholders, i.e., in the box: the shift between agriculture and livestock as the most productive use; in other words, with the environmental conditions self-depicted by stakeholders, a slight difference in annual climate causes a shift in the most productive use between agriculture and livestock.

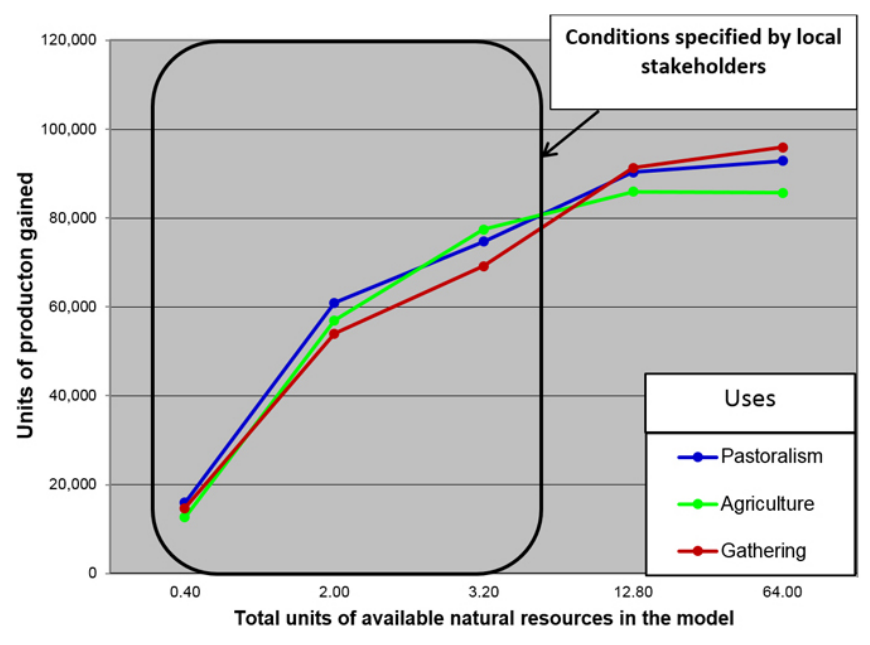

This variability results in highly variable spatial productivity (Fig. 9), which is the product of many different sources of diversity and uncertainty (d'Aquino and $\mathrm{Bah}$, in press): climatic uncertainty, the range of different landscapes, the varying location of key resources, the variety of resource uses, and, depending on the season, users' mobility, and finally, changes in user density. Thus, the self-designed simulation support describes a situation in which a particular land use may have certain advantages depending on the prevailing environmental conditions, and a particular landscape may be advantageous for a particular use, but only with a combination of particular environmental conditions, such as rainfall in the year concerned, user density, or the location of certain key resources. Certain ecological units may be a key resource for a particular type of production but only if used in a particular season. The overall long-term productivity balance relies on certain key resources, like the use of wetlands for agriculture 
Fig. 9. Variations in landscape production (y-axis: productivity units), as a function of land use, user density (x-axis), and the scarcity of environmental resources. Because the $\mathrm{x}$ axis represents increasing user density in the computer model, looking at the curves from left to right, one can monitor the effect of increasing user density on the productivity of each local area. The local areas are the eight subdivisions of a board map (Fig. 2). Productivity increases with an increase in user density, as shown by the individual graphs from left to right, because more users exploit available resources, and overall the curves increase. However, some graphs show a local area with weaker growth. From top to bottom, the graphs are arranged according to the different natural resource parameters applied during the simulation. The worst environmental conditions are in the top graphs. Thus environmental scarcity decreases from top to bottom, see the arrow on the left side of the chart. First, one can see that when environmental conditions worsen, i.e., from the bottom to the top graphs, the differences between the landscapes become greater. Moreover, in these conditions of resource scarcity, depending on the activity, the same landscape will not always be the most advantageous (see colored curves). More generally, the diversity of the landscape curves presented underlines the fact that the advantageous features of a particular landscape at a particular time are the result of a complex combination of factors that changes as a function of each different combination of scarcity, land uses, and user densities.

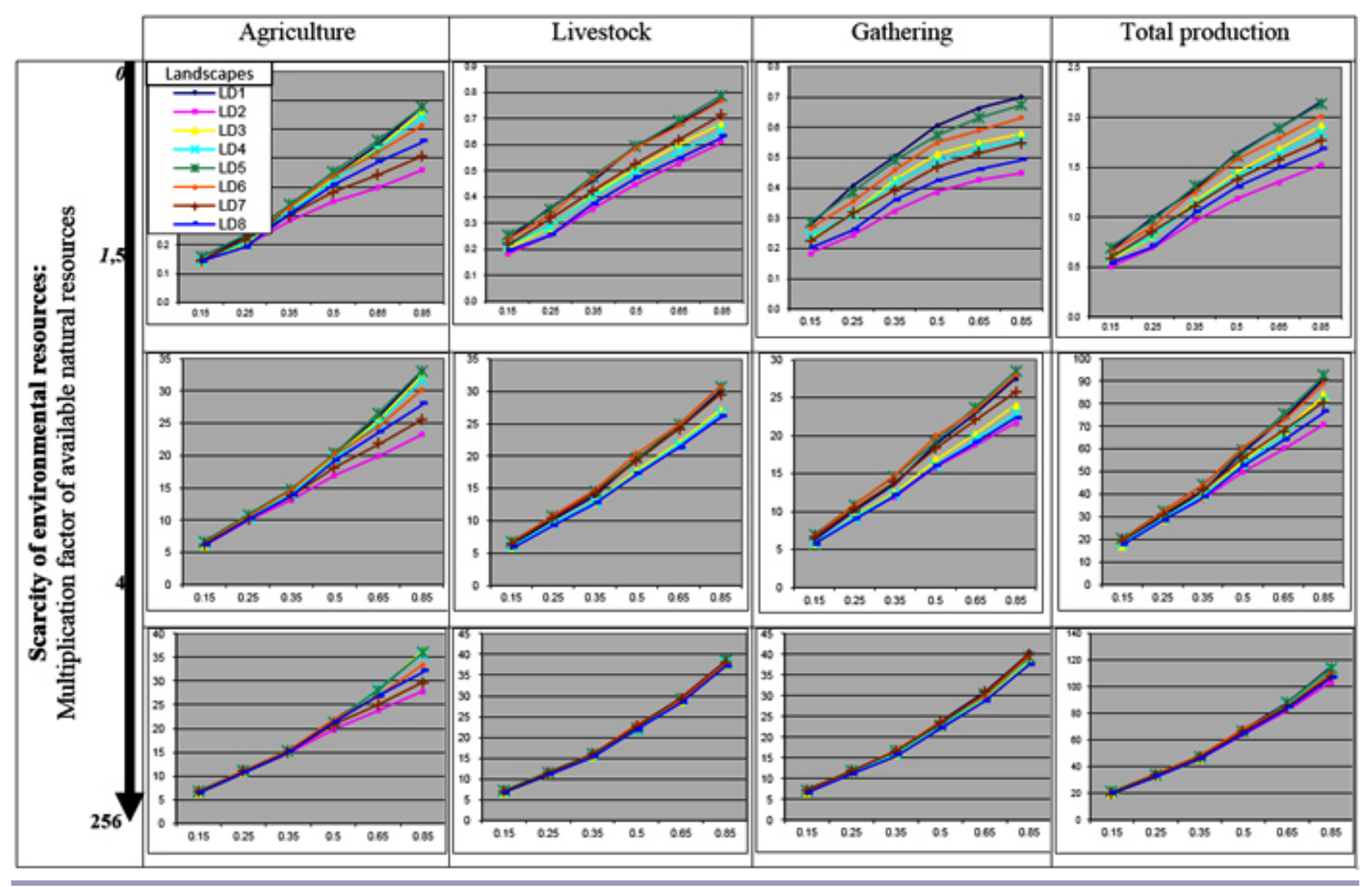

in wetter years, wetlands being unevenly distributed in space, but also the use of wetlands for gathering natural products in drier years, dry years being unevenly distributed in time.

Indeed, a more detailed run of the computerized version of the game (d'Aquino and Bah, in press) demonstrated that the selfdesigned model is a true model of nonequilibrium ecological dynamics, shaped by a complex combination of specific features characteristic of drylands uncertainty:
- There is no general economic advantage of any particular use. Model outputs underlined the fact that the most profitable use differs not only depending on annual rainfall, resource scarcity, and the density of users, but also on the spatial structure of the ecological landscape, thus confirming the value of multipurpose use in this kind of uncertain environment.

- No specific type of landscape has an overriding economic advantage. The spatial combination of variability and 
uncertainty results in complex variability of landscape potentialities that depend on the type of use and exploitation rate, as well as on resource scarcity and annual rainfall. This means the potentially best parcels of land and landscapes change from one year to the next depending on subtle environmental conditions and uses.

- The environmental potentialities are unforeseeable because the above features are combined in such complex and varying ways.

- Last but not least, the future sustainability of the whole agrarian system depends on specific access to some restricted space-time resource niches. A very remarkable Sahelian environmental uncertainty feature was revealed by this self-designed model: long-term yield depends entirely on a few resource niches that are spatially and temporally rare, such as specific wetlands that can be used for agricultural purposes in the wet season in years with high rainfall and for livestock in years with moderate rainfall, or sandy land for grazing livestock in the dry season in years with low rainfall. Drylands researchers have long reported this specific environmental context in which key high value resources are found alongside low value extensive resources (Scoones 1995, Mehta et al. 1999, Dougill et al. 2010). Thus, the stakeholders' intuitive modeling proved its relevance, even based on such fine features. Moreover, it now provides a simulation support that summarizes this environmental specificity in a user-friendly frame, and hence makes it more appropriate for inclusion in policy frameworks and resilience modeling.

Consequently, although the local self-designers did not intentionally conceptualize these particular uncertainty features, in self-depicting their concerns about uncertainty, they designed a model that was qualitative but nevertheless matched the researchers' description of the characteristics of Sahelian uncertainty. Furthermore, their model summarizes these uncertainty features in a very precise form that allows environmental management principles and theories to be tested, because these features are embedded in a qualitative and user-friendly platform based on the same features as games in experimental economics.

\section{The emergence of first indigenous principles for collective rules from the self-simulation process}

Because the modeling platform is shaped by the stakeholders themselves, it is easy for them to use and is consequently a powerful support to help stakeholders reflect among themselves on the best environmental policies to enhance drylands sustainability. At the same time, it tests drylands peoples' ability to design innovative principles of environmental management drawing on the historical ability of their society to surf on uncertainty. Thus, after selfdesigning a multiscale model of environmental uncertainty, stakeholders use the model they have crafted to test, in the form of a game, scenarios of environmental policies they would like to implement to improve their current situation.

The outputs of these first experiments are rules the participants tailored and tested. Participants naturally introduced unconventional environmental management principles: first, they intentionally kept multiuse and multiuser access to land because of the spatial uncertainty and variability of their environment. They then agreed on a priority principle for collective regulation: each area had a priority use or user but with a soft restriction, meaning that all users could access the area but were responsible and answerable for not disturbing the priority use or user. As one participant remarked, this means freeing up the zoning.

Another highly innovative proposal, shaped by the participants, that emerged was distinguishing a soft, flexible common law, similar to the priority zoning, to be applied in standard areas and years, and on the other hand, common ownership with strict collective rules for rare and vital spacetime resource niches. Participants listed the following vital space-time niches: exceptional rainfall in drought years, certain local wetlands in years with high rainfall, other types of wetlands in drought years, particular regional spots of pasture biodiversity that play an essential role in pastoral productivity, and bush resources for gathering in the dry season.

These critical space-time resources belong to a common pool and are controlled by strict allocation rules in such a way that everybody profits from partial access. The distinction between the two regulation systems applies at all management scales, from local districts to natural regions and beyond, to the international Sahel. The details of these regulations and their overlapping regimes are not yet finalized and require further investigations in a new set of simulation workshops, but they already describe general natural resources management that distinguishes between two regulation systems: the first applies in normal situations, i.e., reasonable environmental conditions, when rules of access can be softened and controlled using the original priority principles, and the second applies in a critical situation that can occur at a seasonal, annual, or regional scale.

This unusual indigenous proposal leads us to a peculiar multilevel perspective. Although some of these microspots of resources may be too small to be integrated efficiently at regional or even at local management scales, by combining particular rules for microspecificities within a generally flexible regulation, these Sahelian stakeholders propose an interesting multilevel form of natural resources management, and they appear to have the necessary experience to put it into practice.

Obviously these initial results, i.e., the emerging policy principles, require deeper collective adjustments to become 
operational. Scholars' expertise and policy makers' points of view will also need to be incorporated. However, the indigenous principles of environmental management drawn up by the stakeholders are already sufficiently innovative to fuel the current Senegalese debate about land tenure reforms.

\section{DISCUSSION: THE CHALLENGES OF A MULTILEVEL POLICY DESIGN}

\section{Implementation conditions}

The kind of role-playing game we used has been successfully tested all over the world in the last decade (see http://www. commod.org). When participatory approaches succeed, the main question that arises is whether they are reproducible because success is always embedded in the local features of a society. Of course, like any other participatory approach, the success of the self-design process depends on the facilitator's awareness of the social background, and this usually takes a few months to acquire. However, mobilizing the participants can only succeed if the issue proposed for discussion is a real issue for them (Kok et al. 2007). What we are describing is not an awareness approach but a support for a collective discussion about the participants' own issues. Indeed, the only true obstacles to this kind of approach are, first, that the participants must already have the same aims and feel the need to be involved. In the case of policy design, in some societies, very local users may be not interested in being involved in policy design, even though the policy will have an impact on their livelihoods. The second obstacle is the difficulty for facilitators to avoid incorporating their own points of view when framing the process, either intentionally, for example, with an environmental aim, or subconsciously.

\section{From acknowledging indigenous knowledge to epistemological questioning}

These outputs first led us to discuss the accuracy of indigenous knowledge for resilience thinking. It has long been known that valuable ecological knowledge is embedded in traditional communities (Johannes 1989, Gadgil et al. 1993, Colding and Folke 1997, Berkes and Folkes 1998, Berkes et al. 2000). However, the concept of indigenous knowledge can be defined in different ways. It can refer to empirical local knowledge, for example, about useful medicinal plants; it can also refer to empirical techniques, for example, ways to use a tree for fodder without weakening it; it can also refer to deeper behaviors, like the ways a community is organized to survive in a particular context; and last, in its deepest meaning, it can refer to the particular philosophy of a society, for example, that society's relations with nature and with the Earth. Each of these perceptions of indigenous knowledge depends on the issue, but also draws on different ways of evaluating nonscientific knowledge, i.e., from considering it as mere shrewdness to believing it to be a different but valuable worldview. The self-design stance we propose reflects the latter evaluation.
Some traditional societies have also built an institutional system specifically adapted to the deep uncertainty of natural resources (Mehta et al. 1999). Thus, drylands populations have created a complex pattern of institutions and rules that operate at different scales, with different degrees of intensity, and which concern the management of different portions of the landscape (Thébaud and Batterbury 2001). This complex environmental management has the ability to respond dynamically to social and environmental risks and uncertainties (Scoones 2004, Fraser et al. 2006, Nylong et al. 2007), whereas modern attempts at corporate management based on territorially defined pastureland limit flexibility and adaptability to such an extent that they cannot be considered a huge success (Perkins and Thomas 1993, Dougill et al. 1999, Fraser et al. 2006, Hesse and Thébaud 2006).

Rather than referring to ingenious local practices such as how to use particular pastures or how to preserve the soil, we use traditional knowledge to describe an institutional aptitude for adaptability, which allows, and can manage, flexible practices, rules, and institutions (Berman et al. 2012). This institutional ability could be very useful in our modern search for adaptability if we are able to grasp the fundamental features of this way of thinking (Berkes and Folke 1998). However, this does not mean that we simply need to take over the present or past rules of access designed by these societies because they were shaped for local contexts. Today, even the rules and practices of drylands societies may be less suited to changes in demographics and/or in the climate, as well as to the need for increased productivity. What we should do is incorporate the way these populations think about adaptability, with which they preserve flexibility by reinventing soft flexible systems of rules to surf on uncertainty. This could help improve our way of implementing resilience thinking and coadaptive management at both the management and policy scales.

However, as a deep-rooted feature of society, this particular form of indigenous knowledge remains very difficult to capture. This core feature of drylands society is not rooted in its regimes and rules, but in the intuitive principles according to which negotiations, regimes, and rules are contextually and iteratively designed, managed, and regularly redesigned. Hence, it is much more difficult to capture this way of thinking than to acquire knowledge about contextual practices and rules. In fact, our western way of thinking may create fundamental difficulties. Is our mental framework able to conceptualize a management structure without thinking about hierarchical embedded scales and nested institutions? With our western background, the open-scale, spatial representation we presented may be instinctively interpreted as vague and somehow not rigorous. Indeed, even though several sound theoretical works have been dedicated to this way of thinking (Funtowicz and Ravetz 1994, Röling 1996, Chambers 1997, Gunderson and Holling 2000, Walker et al. 2004), we may not know how to practically design and even perhaps think about 
this kind of translevel and overlapping approach to environmental management (Berkes 2002). On the other hand, drylands societies have succeeded in doing so, and it is an integral part of their mind framework, their own instinctive perception of how to rule a collective organization. So who better to draw on their complex background of 'fuzzy' institutional adaptability to shape modern policy regimes and rules adapted to the new conditions of uncertainty?

To some, this question may be incompatible with the challenge of eliciting indigenous knowledge because reformatting indigenous management principles in a western policy framework tends to destroy local uniqueness rather than preserve it. In fact, embedding indigenous frameworks in a policy framework implies not seeking to preserve the entire indigenous system within the policy framework, but first appreciating the value of some of its unique features and then attempting to reframe as much as possible the policy framework according to these interesting indigenous values and principles. In other words, hybridizing worldviews.

Even when this challenge is acknowledged, a methodological problem arises. How to help indigenous thinking express its ability to manage uncertainty without it being distorted by our instinctive multilevel, i.e., nested, framework? After several decades of participatory experience, we believe the main obstacle is how to avoid deforming the indigenous framework with our unconscious scientific background. Outputs of participatory approaches are still too influenced by facilitators' points of view. Certainly, many methods and approaches let stakeholders express themselves for a variety of goals that range from: involving stakeholders in the choice of goals and agendas; methods that incorporate empirical knowledge in the scholar's knowledge structure; stakeholders can explore the scholar's analysis; and some ask stakeholders to express their needs and points of view. Many of these approaches tend to enable stakeholders to take ownership of scientific knowledge or to contextualize scientific knowledge with local additions (Fraser et al. 2006, Stringer et al. 2006, Medema et al. 2008), which is respectable and useful but not appropriate for our goal, which is eliciting indigenous knowledge. Indeed, participatory approaches that really aim to elicit local knowledge are rare (Lynam et al. 2002, 2007). Moreover, concerning the major obstacle of limiting the facilitator's influence, most approaches have not sufficiently explicitly questioned to what extent they let people incorporate part of their empirical knowledge in the facilitator's scientific framework (Gardners and Lewis 1996, Agrawal and Gibson 1999, Selamna 1999, d'Aquino 2007). Thus, we must pursue this unaccomplished goal by designing methods that allow unusual worldviews of environmental management to be expressed (Hagmann et al. 2002, Wakeford and Pimbert 2004, Reed et al. 2008, Scoones 2009).

The self-design approach takes up this methodological challenge by supporting people in designing their own conceptual settings and then using these endogenous settings to define their own regulation options. We believe that a major requirement of this methodological approach is limiting the influence of external scientific perspectives on the stakeholders' eliciting process. The first milestone is then making sure that very limited external scientific data and knowledge are incorporated during the diagnostic process, so that the participants' framework is not spoiled by exogenous points of view. In the self-design approach, adding scientific knowledge and data is only appropriate when the local framework and model are sufficiently solid to withstand the influence of prevailing scientific opinion. The second milestone is still trickier: limiting the influence of the facilitator, like that of the scientist, on the stakeholders' eliciting process. In fact, whatever the approach, simply by establishing a dialogue, the facilitator already influences the participants' reactions. This is a fact that scientists simply must understand. Consequently, the only scientific way to tackle this influence is to acknowledge it and then carefully and rigorously limit and control it. We need to rigorously check the very limited questions we toss out in front of participants (Fig. 4).

However, some tricky epistemology issues arise from this kind of maieutic process (d'Aquino and Bah 2013a): faced with such a deep iterative analysis, researchers find it very difficult to adhere to a sufficiently rigorous process. For this reason, from our ten years of experience with this kind iterative modeling, we have extracted some sound principles to ensure a rigorous procedure (Étienne 2011) and applied a monitoring framework that makes every researcher's choice of social setting explicit and expressible in a refutable form. Thus, why and how should each form of knowledge be used and at what stage, why and how should the different stakeholders' points of view and goals be incorporated in the development of the appraisal process, and so on. Some methodological supports, like our Rainbow Spiral (von Korff et al. 2010) may be helpful in this regard. Nevertheless, even though this self-modeling process enables the expression of indigenous frameworks, we still need to know how to incorporate scientific knowledge at a later stage, and in our particular case, this is the knowledge of the dynamics of natural resources depletion under increasing pressure. Indeed, in our experience, the stakeholders themselves often want scientific knowledge when they reach a stage in their self-appraisal process in which this type of knowledge serves a purpose, for instance, when in their simulations, increasing the production of fodder becomes indispensable for sustainability (Corniaux et al. 2003). However, in some cases, local people may not acknowledge the authenticity of certain environmental facts (Dray et al. 2007). In such cases, the first part of the solution may be helping people to assimilate a multiscale view of their problem because this will reveal aspects that are not visible at their usual scale of perception. Another part of the solution may be for scholars to reorganize their approach in a more 
comprehensive framework (d'Aquino and Bah 2013a) by starting with a true codefinition of the priority issue that really takes local priorities and points of view into account, and not only the scholars' economic and ecological viewpoints (see post-normal attitude: Funtowicz and Ravetz 1994).

\section{Back to the policy challenge}

The last hurdle in this kind of policy design is embedding local proposals in the policy making process. Indeed, it is difficult to change policy makers' ways of thinking about regulations, i.e., privatization and closure of landscapes, zoning land for separate uses, enforcing static carrying capacities, corporate management linked to territorially delimited pastures, and formalized nested regulatory structures, all measures that restrict flexibility and adaptability. Despite the successes of the first self-designing process experimented at the local level in 2000, which subsequently publicized a new form of local land use management and zoning to other Sahelian countries (d'Aquino and Papazian 2012), the basic structure of the policy, such as the legal access rights, has still not changed. Thus, the success of the self-designed approach in developing local management tools has highlighted the need to change the environmental management paradigm at a more general level. This is why a bottom-up self-design is called for. Indeed, if policy makers are involved in the local stakeholders' design, the chances of succeeding in embedding indigenous skills about uncertainty in the policy debate will be greater.

\section{CONCLUSIONS AND PERSPECTIVES}

The multilevel self-design process tested in the Sahel succeeded in eliciting the background principles of adaptability. The results, which confirm the relevance of the method and of the simulation support produced, mean that this simulation support can be used to enable stakeholders to design their own operational ideas of policies and then analyze the outputs of the policies using scientific adaptability frameworks.

Another option is the use of this kind of paradigm exchange between indigenous knowledge and scientific knowledge. If indigenous thinking about adaptability can improve our management of adaptability, it should be included in the resilience-thinking framework. Pursuing this goal may lead to the use of the self-designed process not only to elicit indigenous points of view, but also to facilitate constructive exchanges with other bodies of knowledge on environmental management. Indeed, the self-design process translates a part of indigenous knowledge into a qualitative language and could do the same with other forms of knowledge with the aim of achieving better mutual understanding and exchange. On one hand, theories of environmental management can be formalized in the form of a rules scenario that can then be used in the self-designed game, and subsequently, easily debated with the players. On the other hand, empirical scenarios formalized by indigenous players can be assessed in an economic and juridical framework, and can fuel scientific debate about adaptability and resilience. Thus, the next step in our work in Senegal is to analyze to what extent these empirical principles of adaptability management can be transformed into practical rules and institutions for resilience and coadaptative management policies.

More work remains to be done than the work accomplished up to now. Nonetheless, the very first results confirm the value of this approach: first, some innovative participatory methods enable stakeholders to use their indigenous way of thinking to design a modern model of environmental management; second, their model may provide new insights into how to design flexible rules to manage uncertainty. In point of fact, the entire methodological framework is an attempt to find a better way for future hybridization of scientific knowledge and indigenous capacity for adaptability, by taking the first steps toward creating an amenable arena for a more comprehensible exchange between different sources of knowledge, toward the cobuilding of new "post-normal" knowledge.

Responses to this article can be read online at: http://www.ecologyandsociety.org/issues/responses. $\mathrm{php} / 5876$

\section{LITERATURE CITED}

Agrawal, A., and C. C. Gibson. 1999. Enchantment and disenchantment: the role of community in natural resource conservation. World Development 27:629-649.

Barreteau, O., M. Antona, P. d'Aquino, S. Aubert, S. Boissau, F. Bousquet, W. Daré, M. Étienne, C. Le Page, R. Mathevet, G. Trébuil, and J. Weber. 2003a. Our companion modelling approach. Journal of Artificial Societies and Social Simulation $6(2)$.

Barreteau, O., C. Le Page, and P. d'Aquino. 2003b. Roleplaying games, models and negotiation processes. Journal of Artificial Societies and Social Simulation 6(2).

Basset, T. J., and D. E. Crummey, editors. 1993. Land in African agrarian systems. University of Wisconsin Press, Madison, Wisconsin, USA.

Behnke, Jr., R. H., I. Scoones, and C. Kerven. 1993. Range ecology at disequilibrium: new models of natural variability and pastoral adaptation in African savannas. Overseas Development Institute, London, UK.

Berkes, F. 2002. Cross-scale institutional linkages: perspectives from the bottom-up. Pages 293-321 in Committee on the Human Dimensions of Global Change, E. Ostrom, T. Dietz, N. Dolsak, P. C. Stern, S. Stonich, and E. U. Weber, 
editors. The drama of the commons. National research Council, Washington, D.C., USA.

Berkes, F., and C. Folke, editors. 1998. Linking social and ecological systems: management practices and social mechanisms for building resilience. Cambridge University Press, Cambridge, UK.

Berkes, F., J. Colding, and C. Folke. 2000. Rediscovery of traditional ecological knowledge as adaptive management. Ecological Applications 10(5):1251-1262. http://dx.doi. org/10.1890/1051-0761(2000)010[1251:ROTEKA]2.0.CO;2

Berman, R., C. Quinn, and J. Paavola. 2012. The role of institutions in the transforming of coping capacity to sustainable adaptative capacity. Environmental Development 2:86-100. http://dx.doi.org/10.1016/j.envdev.2012.03.017

Bousquet, F., O. Barreteau., P. d'Aquino, M. Étienne, S. Boissau, S. Aubert, C. Lepage, D. Babin, and J. C. Castella. 2003. Multi-agent systems and roles games: collective learning processes for ecosystem management. Pages 248-285 in M. A. Janssen, editor. Complexity and ecosystem management: the theory and practice of multi-agent approaches. Edward Elgar, Cheltenham, UK.

Chambers, R. 1997. Whose reality counts?: putting the first last. Intermediate Technology, London, UK.

Colding, J., and C. Folke. 1997. The relations among threatened species, their protection, and taboos. Conservation Ecology 1(1): 6. [online] URL: http://www.consecol.org/vol1/ $\underline{\text { iss } 1 / \text { art6 }}$

Corniaux, C., P. d'Aquino, and G. Molenat. 2003. Towards an adaptation of rangelands management and scientists interventions in a new agro-pastoral context. Case study in rice-based farming systems in the Delta of Senegal River. In Proceedings of the VII International Rangeland Congress, Durban, South Africa. Society for Range Management, Boulder, Colorado, USA.

d'Aquino, P. 2007. Some novel information systems for the empowerment of a decision-making process on a territory: outcomes from a four years participatory modeling in Senegal. ICFAI Journal of Knowledge Management 5(4):80-89.

d'Aquino, P., and A. Bah. 2013a. A bottom-up participatory modelling process for a multi-level agreement on environmental uncertainty management in West Africa. Journal of Environmental Planning and Management 56 (2):271-285. http://dx.doi.org/10.1080/09640568.2012.665361

d'Aquino, P., and A. Bah. 2013. Land policies for climate change adaptation in West Africa: a multi-level companion modelling approach. Simulation and Gaming 44(2-3):391-408. http://dx.doi.org/10.1177/1046878112452689
d'Aquino, P., and A. Bah. In press. The value of stakeholders' self-modelling to model environmental uncertainty. The case of the Sahelian context. Environmental Modelling and Software.

d'Aquino, P., C. Le Page, and F. Bousquet. 2002. A novel mediating participatory modeling: the self-design process to accompany a collective decision-making. International Journal of Agriculture and Resources Governance and Ecology 2(1):59-74 http://dx.doi.org/10.1504/IJARGE.2002.000022

d'Aquino, P., C. Le Page, F. Bousquet, and A. Bah. 2003. Using self-designed role-playing games and a multi-agent system to empower a local decision-making process for land use management: the SelfCormas experiment in Senegal. Journal of Artificial Societies and Social Simulation 6(3). [online] URL: http://jasss.soc.surrey.ac.uk/6/3/5.html

d'Aquino, P., and H. Papazian. 2012. A ten-years-after impact analysis of a Companion Modelling approach. Final evaluation report. Ifad, Cirad, Rome. [online] URL: http://hal. archives-ouvertes.fr/docs/00/87/53/54/PDF/How participation_Impacts_Empowerment.pdf

Dougill, A. J., D. S. G. Thomas, and A. L. Heathwaite. 1999. Environmental change in the Kalahari: integrated land degradation studies for nonequilibrium dryland environments. Annals of the Association of American Geographers 89 (3):420-442. http://dx.doi.org/10.1111/0004-5608.00156

Dray, A., P. Perez, C. Le Page, P. d'Aquino, and I. White. 2007. Who wants to terminate the game? The role of vested interests and meta players in the ATOLLGAME experience. Simulation and Gaming 38(4):494-511. http://dx.doi. org/10.1177/1046878107300673

Ellis, J. E., and D. M. Swift. 1988. Stability of African pastoral ecosystems: alternate paradigms and implications for development. Journal of Range Management 41:450-459. http://dx.doi.org/10.2307/3899515

Étienne, M., editor. 2011. Companion modelling: a participatory approach to support sustainable development. QUAE, Versailles, France.

Fairhead, J., and M. Leach. 2005. The centrality of the social in African farming. IDS Bulletin 36(2):86-90. http://dx.doi. org/10.1111/j.1759-5436.2005.tb00202.x

Fraser, E.D.G., A. J. Dougill, W. E. Mabee, M. Reed, and P. McAlpine. 2006. Bottom up and top down: analysis of participatory processes for sustainability indicator identification as a pathway to community empowerment and sustainable environmental management. Journal of Environmental Management 78:114-127. http://dx.doi.org/10.1016/j. jenvman.2005.04.009

Funtowicz, S. O., and J. R. Ravetz. 1994. The worth of a songbird: ecological economics as a post-normal science. 
Ecological Economics 10:197-207. http://dx.doi. org/10.1016/0921-8009(94)90108-2

Gadgil, M., F. Berkes, and C. Folke. 1993. Indigenous knowledge for biodiversity conservation. Ambio 22:151-156.

Gardner K., and D. Lewis. 1996. Anthropology, development and the post-modern challenge. Pluto, London, UK.

Gunderson, L. 1999. Resilience, flexibility and adaptive management. Antidotes for spurious certitude? Conservation Ecology 3(1): 7. [online] URL: http://www.consecol.org/vol3/ $\underline{\text { iss } 1 / \operatorname{art} 7 /}$

Gunderson, L. H., and C. S. Holling. 2000. Panarchy: understanding transformation in human and natural systems. Island, Washington, D.C. USA.

Hagmann, J., E. Chuma, K. Murwiea, M. Connoly, and P. Ficarelli. 2002. Success factors in integrated natural resource management R\&D: lessons from practice. Conservation Ecology 5(2): 29. [online] URL: http://www.consecol.org/ vol5/iss $2 / \operatorname{art} 29 /$

Hesse, C., and B. Thébaud. 2006. Will pastoral legislation disempower pastoralists in the Sahel? International Work Group for Indigenous Affairs, 1/06, 14-23.

Johannes, R. E., editor. 1989. Traditional ecological knowledge: a collection of essays. International Conservation Union (IUCN), Gand, Switzerland.

Juul, K. 2005. Transhumance, tubes and telephones: droughtrelated migration as a process of innovation. Pages 112-134 in Q. Gausset, M. A. Whyte, and T. Birch-Thomsen. Beyond territory and scarcity: exploring conflicts over natural resource management. Nordic Africa Institute, Uppsala, Sweden.

Kok, K., R. Biggs, and M. Zurek. 2007. Methods for developing multi-scale participatory scenarios: insights from Southern Africa and Europe. Ecology and Society 12(1): 8. [online] URL: http://www.ecologyandsociety.org/vol12/iss1/ $\underline{\operatorname{art} 8 /}$

Lynam, T., F. Bousquet, P. d'Aquino, O. Barreteau, C. Le Page, F. Chinembiri, and B. Mombeshora. 2002. Adapting science to adaptive managers: spidergrams, belief models, and multi-agent systems modeling. Conservation Ecology 5(2): 24. [online] URL: http://www.consecol.org/vol5/iss2/art24/

Lynam, T., W. De Jong, D. Sheil, T. Kusumanto, and K. Evans. 2007. A review of tools for incorporating community knowledge, preferences, and values into decision making in natural resources management. Ecology and Society 12(1): 5. http://www.ecologyandsociety.org/vol12/iss1/art5/

Martin, V. B., and A. Gynnild, editors. 2011. Grounded theory: the philosophy, method, and work of Barney Glaser. Brown Walker, Boca Raton, Florida, USA.
Medema, W., B. S. McIntosh, and P. J. Jeffrey. 2008. From premise to practice: a critical assessment of integrated water resources management and adaptative management approaches in the water sector. Ecology and Society 13(2): 29. [online] URL: http://www.ecologyandsociety.org/vol13/iss2/ $\underline{\operatorname{art} 29 /}$

Mehta, L., M. Leach, P. Newell, I. Scoones, K. Sivaramakrishnan, and S.-A. Way. 1999. Exploring understandings of institutions and uncertainty: new directions in natural resource management. Institute of Development Studies, Brighton, UK.

Moritz, M., B. R. Kyle, K. C. Nolan, S. Patrick, M. F. Shaffer, and G. Thampy. 2009. Too many people and too few livestock in West Africa? An evaluation of Sandford's thesis. The Journal of Development Studies 45(7):1113-1133. http://dx. doi.org/10.1080/00220380902811058

Mortimore, M. 2005. Social resilience in African drylands livelihoods. Pages 46-69 in Q. Gausset, M. A. Whyte, and T. Birch-Thomsen, editors. Beyond territory and scarcity: exploring conflicts over natural resource management. Nordic Africa Institute, Uppsala, Sweden.

Nylong, A., F. Adesina, and B. Osman Elasha, editors. 2007. The value of indigenous knowledge in climate change mitigation and adaptation strategies in the African Sahel. Institute of Development Studies, Brighton, UK.

Ostrom, E. 2005. Understanding institutional diversity. Princeton University Press, Princeton, New Jersey, USA.

Perkins, J. S., and D. S. G. Thomas. 1993. Spreading deserts or spatially confined environmental impacts? Land degradation and cattle ranching in the Kalahari desert of Botswana. Land Degradation and Development, 4 (3):179-194. http://dx.doi.org/10.1002/ldr.3400040307

Reed, M. S., A. J. Dougil, and T. R. Baker. 2008. Participatory indicator development: what can ecologists and local communities learn from each other? Ecological Applications 18:1253-1269. http://dx.doi.org/10.1890/07-0519.1

Röling, N. 1996. Towards an interactive agricultural science. European Journal of Agricultural Education and Extension 2 (4):35-48. http://dx.doi.org/10.1080/13892249685300061

Selamna, N.-E. 1999. Relativism in agricultural research and development: is participation a post-modern concept? Overseas Development Institute, London, UK.

Scoones, I., editor. 1995. Living with uncertainty: new directions in pastoral development in Africa. Institute of Development Studies, Brighton, UK.

Scoones, I. 2009. Livelihoods perspectives and rural development. Journal of Peasant Studies 36(1):171-196. http://dx.doi.org/10.1080/03066150902820503 
Stringer, L. C., C. Prell, M. S. Reed, K. Hubacek, E. D. G. Fraser, and A. J. Dougill. 2006. Unpacking 'participation' in the adaptative management of socio-ecological systems: a critical review. Ecology and Society 11(2): 39. [online] URL: http://www.ecologyandsociety.org/vol11/iss2/art39/

Thébaud, B., and S. Batterbury. 2001. Sahel pastoralists: opportunism, struggle, conflict and negotiation. A case study from eastern Niger. Global Environmental Change 11 (1):69-78. http://dx.doi.org/10.1016/S0959-3780(00)00046-7

von Korff, Y., P. d'Aquino, K. A. Daniell, and R. Bijlsma. 2010. Designing participation processes for water management and beyond. Ecology and Society 15(3): 1. [online] URL: http://www.ecologyandsociety.org/vol15/iss3/ $\underline{\operatorname{art} 1 /}$

Wakeford, T., and M. Pimbert. 2004. Prajateerpu, power and knowledge. The politics of participatory action research in development. Part 2. Analysis, reflections and implications. Action Research 2(1):25-46. http://dx.doi.org/10.1177/1476$\underline{750304041066}$

Walker, B., C. S. Holling, S. R. Carpenter, and A. Kinzig. 2004. Resilience, adaptability and transformability in socialecological systems. Ecology and Society 9(2): 5. [online] URL: http://www.ecologyandsociety.org/vol9/iss2/art5/

Westoby, M., B. Walker, and I. Noy-Meir. 1989. Opportunistic management of rangelands not at equilibrium. Journal of Range Management 42:266-274. http://dx.doi. org $/ 10.2307 / 3899492$ 
Appendix 1. Some explanations of the game.

Thanks to its multi-scale representation (see figure 1), the game allows rules, practices and their effects to be represented at the scale of a parcel, farmland (a set of parcels in figure 1), the local district (see the boundary of a district in bold in figure 1), the region (representing a particular regional landscape on each map) and of the whole country (the whole set of maps). Different land uses (represented by different pawns) can be positioned on and moved around the maps by farmer-players, depending on their farming choices and on the land access rules they previously designed for the game. In this spatial environment, local users (the players) use the different parcels depending on the range of possible uses at their disposal (different types of farming and livestock rearing, gathering wild products, forestry, environmental use, etc.), depending on the season and on the land access rules laid down by the land policies in the simulation they are running.

During the game sessions, players consume the natural resources shown on the maps that comprise the game board, via a wide range of possible uses (different types of farming and/or livestock rearing, gathering wild products, forestry, environmental use, etc.), depending on the season and on the local, regional and national access regulations they themselves drew up.

Several output indicators are provided. Environmental indicators, such as the quantity of the four natural resources available in each parcel as a function of annual climate conditions, past uses, and potential environmental risks (over-exploitation, bush fire, etc.). Other indicators allow multi-scale assessment of productivity: at the very local scale, the yield each user obtains depends on the land use and on the availability of natural resources in the parcel concerned, but also on socio-economic aspects, such as the food self sufficiency of the user, and, at other scales (district, region and country), total yield and the productivity of each type of land use.

The basic game components made available to the players are:

- A game board comprising separate squared maps (up to five maps), representing different benchmark landscapes in the region;

- Colored pawns representing different land uses (extensive or intensive agriculture, livestock rearing, hunting, gathering, etc.);

- Small marbles, representing units of capital earned with different types of uses. The marbles are added to the family resources box at the end of each season. The number of marbles depends on the success of the uses chosen by the family;

- Plastic boxes, representing each player's « family box », where each player's capital (represented by marbles) is visible;

- A dice to introduce an element of chance in the climate scenarios;

- Yellow "events cards", representing any sort of event or risk the participants wish to include (bush fire, changes in the price of goods, the arrival of migrants, etc.);

- A scenario building framework to design scenarios concerning land access rules;

- "Red cards" the players receive when they do not achieve food sufficiency;

- Participatory charts to analyze and summarize the impacts of scenarios on the different assessment indicators linked to the range of issues defined in stage 1.

The players are distributed on the different regional maps to account for the different regional contexts included in their game and/or simulations.

There are three stages to the game that match the three Sahelian seasons: the rainy season, the cool dry season, and the hot dry season. During each stage, the players place colored pawns on the maps, according to the choice of uses they made based on their capital and the family work force. At the end of each stage, the game master counts up the yield each player has 
produced, which will vary depending on the uses they chose and on the natural resources available in the parcels they used (depending on the kind of landscape, but also on rainfall and past uses of the parcels).

The rules governing the production enabled by each use were checked and validated by the players in the first stage of the game. The game master scores each player's results by counting the pink marbles in each family box, subtracting some of them to represent food sufficiency needs in relation to the size of each family. At this point, climate changes are introduced into the game through "events cards", i.e. the unpredictable events that occur during the year being simulated: extreme rainfall events or drought, off-season rains, a very dry wind, etc.

After several simulated years, participants examine the results of each indicator of environmental policy challenges they previously defined:

- Economic indicators: the capital and food sufficiency accumulated by each player; overall production and all forms of productivity at each scale of the game (grassroots user, local district, regional landscape, the whole country);

- Environmental indicators: the overall qualitative environmental status of each parcel in the different regional landscapes;

- Social and cultural indicators: profile and rate of losers (users, local districts, regions, etc., but also more complex phenomena spontaneously simulated by players during the game sessions, such as conflicts, agreements, respect of collective rules, etc.

The participants then use the game to shape and test improvement scenarios concerning users' practices, land access rules, or new facilities or incentives to improve the results of the indicators. This implies accounting for the whole range of points of view and the scale of management issues: families, local districts, regions, and the country as a whole. Indeed, participants play two different roles: individually they play the role of users, and together they play the game master, defining scenarios and changing the rules of the game (land access, users' practices, facilities included on the maps, etc.). 